\title{
Evidence for a Tetrameric Structure of Recombinant NMDA Receptors
}

\author{
Bodo Laube, Jochen Kuhse, and Heinrich Betz \\ Department of Neurochemistry, Max-Planck-Institute for Brain Research, 60528 Frankfurt/Main, Germany
}

The amino acids L-glutamate and glycine are essential agonists of the excitatory NMDA receptor, a subtype of the ionotropic glutamate receptor family. The native NMDA receptor is composed of two types of homologous membrane-spanning subunits, NR1 and NR2. Here, the numbers of glycine-binding NR1 and glutamate-binding NR2 subunits in the NMDA receptor hetero-oligomer were determined by coexpressing the wildtype (wt) NR1 with the low-affinity mutant NR1 ${ }^{\text {Q387K }}$, and the wt NR2B with the low-affinity mutant NR2B ${ }^{\text {E387A }}$, subunits in $\mathrm{Xe}$ nopus oocytes. In both cases, analysis of the resulting doseresponse curves revealed three independent components of glycine and glutamate sensitivity. These correspond to the respective wild-type and mutant affinities and an additional intermediate hybrid affinity, indicating the existence of three discrete receptor populations. Binomial analysis of these data indicates the presence of two glycine and two glutamate binding subunits in the functional receptor. In addition, we analyzed the inhibitory effects of the negative dominant NR1 ${ }^{R 505 K}$ and NR2B ${ }^{\mathrm{R} 493 \mathrm{~K}}$ mutants on maximal inducible whole-cell currents of wt NR1/NR2B receptors. The inhibition profiles obtained on expression of increasing amounts of these mutant proteins again were fitted best by assuming an incorporation of two NR1 and two NR2 subunits into the receptor hetero-oligomer. Our data are consistent with NMDA receptors being tetrameric proteins that are composed of four homologous subunits.

Key words: mutagenesis; subunit stoichiometry; NMDA receptor; glutamate; channel assembly; electrophysiology; agonist affinity; Xenopus oocyte
Both the propagation of action potentials and synaptic transmission are crucially dependent on the transient opening of voltageand ligand-gated ion channel proteins that regulate the movement of selected ions across the neuronal plasma membrane (Hille, 1992). Typically, ion channels are multisubunit proteins, the composition of which can vary with cell type and stage of development; the number of subunits and their stoichiometry, however, are highly conserved within a given channel protein family. For example, voltage-gated potassium channels are always tetrameric proteins, postsynaptic nicotinic acetylcholine receptors are composed of five homologous subunits, and gap junction proteins mediating coupling at electrical synapses contain six identical or related subunits (Betz, 1990; MacKinnon, 1995).

In the mammalian brain, excitatory neurotransmission is predominantly mediated by members of the glutamate receptor superfamily of ligand-gated ion channels. Different subtypes of these receptors are found at $>50 \%$ of all chemical synapses in the CNS. Based on pharmacological studies, ionotropic glutamate receptors have been grouped into three distinct subfamilies: AMPA receptors, kainate receptors, and NMDA receptors (Watkins et al., 1990; Gasic and Hollmann, 1992). Of these, the NMDA receptors have received special attention: they have been implicated in synaptic plasticity and memory formation because of properties that qualify them as coincidence detectors (Olney,

Received Dec. 5, 1997; revised Jan. 23, 1998; accepted Feb. 4, 1998.

This research was supported by Deutsche Forschungsgemeinschaft (SFB 169), Human Capital and Mobility Program (Contract ERBCHRXCT930167), and Fonds der Chemischen Industrie. We thank Drs. S. Nakanishi and M. Mishina for supplying the NR1 and NR2B cDNAs, Dr. R. Harvey for critical reading of this manuscript, and M. Baier and H. Reitz for secretarial assistance.

Correspondence should be addressed to Heinrich Betz, Department of Neurochemistry, Max-Planck-Institute for Brain Research, Deutschordenstrasse 46, 60528 Frankfurt/Main, Germany.

Copyright (C) 1998 Society for Neuroscience $\quad 0270-6474 / 98 / 182954-08 \$ 05.00 / 0$
1990; Nakanishi, 1992). In addition to membrane depolarization, NMDA receptors require the simultaneous binding of both glutamate and the coagonist glycine for efficient gating (Johnson and Ascher, 1987; Kleckner and Dingledine, 1988). Site-directed mutagenesis has localized the glycine and glutamate binding sites of NMDA receptors to homologous segments of its principal subunits NR1 and NR2 (Kuryatov et al., 1994; Wafford et al., 1995; Hirai et al., 1996; Laube et al., 1997). The NR1 subunit is expressed in several splice variants throughout the CNS (Durand et al., 1992; Nakanishi et al., 1992; Sugihara et al., 1992; Hollmann et al., 1993). The NR2 subunit exists in four isoforms encoded by different genes (NR2A-D) that create functional and regional heterogeneity of NMDA receptors (Kutsuwada et al., 1992; Meguro et al., 1992; Monyer et al., 1992). Despite considerable progress in their functional analysis, the number and stoichiometry of NMDA receptor subunits are still a matter of debate.

Mutational analysis from our laboratory has shown that position 387 of the NR1 and the NR2B subunits is crucial for high-affinity binding of glycine and glutamate, respectively (Kuryatov et al., 1994; Laube et al., 1997), whereas substitution of a conserved arginine (NR1 ${ }^{\mathrm{R} 505}, \mathrm{NR}^{2} \mathrm{~B}^{\mathrm{R} 493}$ ) (Hirai et al., 1996; Laube et al., 1997) abolishes channel function. Here, we have exploited these findings to determine the numbers of NR1 and NR2 subunits in recombinant NMDA receptors generated by Xenopus oocytes. By coexpressing different ratios of wild-type (wt) with low-affinity or negative dominant mutant NR1 and NR2B subunits, we find that two copies of both NR1 and NR2B are contained in recombinant heteromeric NMDA receptor channels. Thus, our data indicate that NMDA receptors are tetrameric proteins.

\section{MATERIALS AND METHODS}

Voltage-clamp recording of agonist dose-response curves from recombinant NMDA receptors generated by coinjection into Xenopus oocytes 


\begin{tabular}{|c|c|c|c|c|c|}
\hline cRNAs injected & $\mathrm{EC}_{50}(\mu \mathrm{M})$ & $n_{\mathrm{H}}$ & $I_{\max }(\mathrm{nA})$ & Fractional current $(\%)$ & $n$ \\
\hline NR1 & $0.52 \pm 0.28$ & $1.6 \pm 0.2$ & $3600 \pm 1000$ & & 9 \\
\hline $\mathrm{NR} 1+\mathrm{NR} 1{ }^{\mathrm{Q} 387 \mathrm{~K}}(5: 1)$ & & & $2400 \pm 1100$ & & 3 \\
\hline HA-component & $0.7 \pm 0.4$ & $1.8 \pm 0.3$ & & $80 \pm 9$ & \\
\hline IMA-component & $38 \pm 21$ & $1.5 \pm 0.5$ & & $20 \pm 9$ & \\
\hline LA-component & n.d. & & & n.d. & \\
\hline $\mathrm{NR} 1+\mathrm{NR} 1^{\mathrm{Q} 387 \mathrm{~K}}(1: 1)$ & & & $1700 \pm 700$ & & 4 \\
\hline HA-component & $0.8 \pm 0.5$ & $1.8 \pm 0.4$ & & $24 \pm 6$ & \\
\hline IMA-component & $51 \pm 17$ & $1.4 \pm 0.3$ & & $48 \pm 9$ & \\
\hline LA-component & $4900 \pm 2200$ & $1.7 \pm 0.6$ & & $28 \pm 7$ & \\
\hline $\mathrm{NR} 1+\mathrm{NR} 1{ }^{\mathrm{Q} 387 \mathrm{~K}}(1: 5)$ & & & $1900 \pm 800$ & & 3 \\
\hline HA-component & n.d. & & & n.d. & \\
\hline IMA-component & $76 \pm 42$ & $1.6 \pm 0.6$ & & $26 \pm 13$ & \\
\hline LA-component & $8000 \pm 3200$ & $1.2 \pm 0.2$ & & $74 \pm 13$ & \\
\hline $\mathrm{NR} 1^{\mathrm{Q} 387 \mathrm{~K}}$ & $7400 \pm 2100$ & $1.5 \pm 0.3$ & $3500 \pm 1400$ & & 4 \\
\hline
\end{tabular}

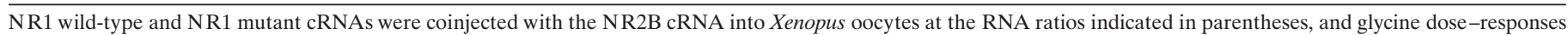

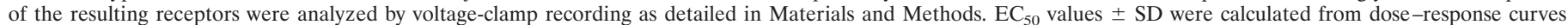

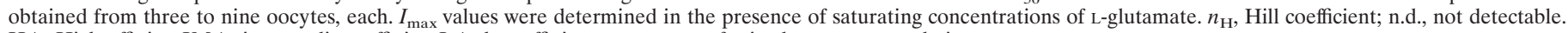
HA, High-affinity; IMA, intermediate-affinity; LA, low-affinity components of mixed receptor populations.

of wt NR1 (Moriyoshi et al., 1991) and NR2B (Kutsuwada et al., 1992) or mutant NR1 ${ }^{\text {Q387K }}$ (Kuryatov et al., 1994), NR1 ${ }^{\text {R505K }}$ (Hirai et al., 1996), and NR2B ${ }^{\text {E387A }}$ and NR2B R493K (Laube et al., 1997) cRNAs was performed as described (Kuryatov et al., 1994). Linearized plasmid DNA of the NR1 and NR2B subunits was used for the in vitro synthesis of cRNAs with the mCAP mRNA Capping Kit (Stratagene, La Jolla, CA) and T7 and T3 RNA polymerases, respectively. cRNA concentrations were adjusted to $50-500 \mathrm{ng} / \mu \mathrm{l}$ by measuring the optical density at 260 $\mathrm{nm}$. For coinjection experiments, appropriately diluted aliquots of the different cRNAs were mixed at the indicated ratios before injection (Kuhse et al., 1993; Laube et al., 1993). The ratio and the amount of injected NR1 and NR2B cRNAs were kept constant. Voltage-clamp recordings of glycine- and glutamate-induced currents in the presence of saturating concentrations of L-glutamate and glycine, respectively, were performed $48 \mathrm{hr}$ after injection in $\mathrm{Mg}^{2+}$-free frog Ringer's solution containing reduced $\mathrm{Ca}^{2+}$ concentrations $(0.9 \mathrm{~mm})$ at a holding potential of $-70 \mathrm{mV}$ (Laube et al., 1993). Under these conditions we obtained a high stability of our recordings for up to $1 \mathrm{hr}$. Parallel experiments in the absence of $\mathrm{Ca}^{2+}$ and after injection of $10 \mathrm{mM}$ BAPTA or preincubation with its membrane-permeant derivative BAPTA-AM revealed that any contribution of $\mathrm{Ca}^{2+}$-activated chloride conductances had no significant effect on apparent agonist affinities (B. Laube, unpublished data). To allow for efficient solution exchanges, the BPS drug application system (Adams and List, Westbury, NY) was used. All experimental values are presented as the mean \pm SD of peak current responses.

For the evaluation of half-maximal effective agonist concentrations $\left(\mathrm{EC}_{50}\right)$ and Hill coefficients $\left(n_{\mathrm{H}}\right)$ from dose-response curves, data from several $(n)$ oocytes were fitted to the Michaelis-Menten equation (1) using the least-squares fit:

$$
I=I_{\max }\left(\frac{[A]^{n_{\mathrm{H}}}}{[A]^{n_{\mathrm{H}}}+\left[\mathrm{EC}_{50}\right]^{n_{\mathrm{H}}}}\right)
$$

where $I$ is current, $I_{\max }$ the maximal current response, and $A$ the agonist concentration.

To calculate dose-response properties for mixtures of NMDA receptors, we used the following equation:

$$
I=\sum_{\mathrm{i}=0}^{\mathrm{j}}\left(f_{\mathrm{i}} \cdot \frac{[A]^{n_{\mathrm{H}}}}{[A]^{n_{\mathrm{H}}}+\left[k_{\mathrm{i}}\right]^{n_{\mathrm{H}}}}\right)
$$

where $f_{\mathrm{i}}$ is the fraction of the total receptors contributed by species i and $k_{\mathrm{i}}$ the apparent equilibrium dissociation constants $\left(\mathrm{EC}_{50}\right.$ values) for agonist binding to a channel species with $i$ mutant subunits $\left(K_{0}, K_{1}, \ldots\right.$ and $\left.K_{\mathrm{i}}\right) . K_{0}$ and $K_{\mathrm{i}}$ were determined by measuring the respective $\mathrm{EC}_{50}$ values of glycine- and glutamate-induced currents through the nonmixed channels. Assuming a random association of subunits, $f_{\mathrm{i}}$ was determined by binominal probability calculation using the least-squares fit method.
The relative concentrations of NR1(wt) and NR1(mutant) or NR2B(wt) and NR2B(mutant) subunits were assumed to correlate with the amounts of cRNAs injected (MacKinnon, 1991).

For experiments involving mixtures of channel species, groups of oocytes were injected with NR1(wt)/NR1(mutant) and NR2B(wt)/ $\mathrm{NR} 2 \mathrm{~B}$ (mutant) cRNAs mixed at the indicated ratios and coexpressed with the corresponding NR2B or NR1 subunit at a NR1/NR2B ratio of 1:3. For statistical analysis, data were subjected to a nonpaired Student's $t$ test using the StatView program (Abacus Concepts, Berkeley, CA). Correlation coefficients for curve fittings were determined using the Levenberg-Marquardt algorithm (Synergy Software, Reading, PA).

\section{RESULTS}

To determine the stoichiometry of glycine-binding NR1 and glutamate-binding NR2 subunits in recombinant NMDA receptors, we coexpressed the wild-type (wt) with low-affinity or negative dominant mutant subunits at different ratios and estimated the number of subunits in, and the relative abundance of, the resulting hybrid receptors by analyzing their agonist response properties.

\section{Glycine response properties of channels generated on coexpression of wt and mutant NR1 with wt NR2B subunits}

To assess the number of NR1 subunits within the NMDA receptor channel, we injected cRNA encoding either the wt NR1 subunit or the low-affinity mutant NR1 ${ }^{\mathrm{Q} 387 \mathrm{~K}}$ together with the NR2B cRNA into Xenopus oocytes. The glycine response properties of the resulting receptors were then analyzed in the presence of saturating concentrations of L-glutamate using voltageclamp recording. When NMDA receptors containing the wt NR1 and NR2B subunits were generated by injection of the respective cRNAs, superfusion of glycine evoked maximal membrane currents $\left(I_{\max }\right)$, with a mean amplitude of $3600 \pm 1000 \mathrm{nA}$ and a half-maximal response $\left(\mathrm{EC}_{50}\right)$ at a glycine concentration of $0.52 \pm 0.28 \mu \mathrm{M}$ (Table 1$)$. A drastic reduction in glycine affinity $\left(\mathrm{EC}_{50}=7.4 \pm 2.1 \mathrm{~mm}\right)$ without a significant change in efficacy $\left(I_{\max }=3500 \pm 1400 \mathrm{nA}\right)$ was obtained when the $\mathrm{NR} 1^{\mathrm{Q} 387 \mathrm{~K}}$ mutant was coexpressed with the wt NR2B subunit (Table 1). These $\mathrm{EC}_{50}$ values are in accord with previous work (Kuryatov et al., 1994). Coinjection of mixtures of wt NR1 and mutant NR1 ${ }^{\text {Q387K }}$ cRNAs was then performed at ratios of 5:1, 1:1, and 
Figure 1. Membrane currents in oocytes expressing heteromeric NMDA receptors generated by coinjection of NR1, $\mathrm{NR} 1{ }^{\mathrm{Q} 387 \mathrm{~K}}$, and NR2B subunits. $A$, Glycineactivated whole-cell currents in the presence of $100 \mu \mathrm{M}$ L-glutamate obtained at a holding potential of $-70 \mathrm{mV}$. Oocytes injected with the wt NR1 and NR1 ${ }^{\mathrm{Q} 387 \mathrm{~K}}$ cRNAs at a ratio of $1: 1$ were superfused with the glycine concentrations indicated above the application bars. Calibration: 200 $\mathrm{nA}, 15$ sec. $B$, Glycine dose-response curves obtained from oocytes injected with NR1 and NR1 ${ }^{\mathrm{Q} 387 \mathrm{~K}}(\mathbf{)})$ cRNAs at ratio of 1:1. Note the triphasic dose-response seen on coexpression of the wt and mutant NR1 subunits. Corresponding $\mathrm{EC}_{50}$ values for the high-affinity (HA), intermediate-affinity (IMA), and low-affinity (LA) components are $0.56 \mu \mathrm{M}, 48 \mu \mathrm{M}$ and $4.8 \mathrm{mM}$, with fractional contributions of 27,44 , and $29 \%$ of the maximal current, respectively. $C$, Glycine dose-response curves recorded from oocytes injected with the NR1 and NR1 $1^{\text {Q387K }}$ cRNAs at a ratios of 5:1 (ם) or 1:5 (A), respectively. In both cases, clearly biphasic dose-response curves were obtained. The corresponding $\mathrm{EC}_{50}$ values of the HA- and IMA-, or IMA- and LA- components are 0.9 and $50 \mu \mathrm{M}$, or $84 \mu \mathrm{M}$ and 7 $\mathrm{mM}$, with fractional current contributions of 79 and $21 \%$, or 26 and $74 \%$, respectively, of the maximal current. In both $B$ and $C$, the solid lines represent least-squares fits of the data to the modified Hill Equation 2. The dotted lines correspond to the dose-response curves of the pure NR1/NR2B and

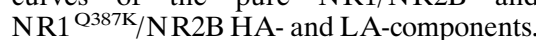
Data from individual oocytes are shown; all measurements were repeated on at least three different oocytes with similar results. The mean $( \pm \mathrm{SD})$ of the $\mathrm{EC}_{50}$ values and the Hill coefficients calculated from these experiments are given in Table 1 . The subunit compositions predicted for tetrameric receptor complexes are indicated schematically $(O$ represents NR1 wt, $\bullet \mathrm{NR} 1^{\mathrm{Q} 387 \mathrm{~K}}$, and :; NR2B).

1:5 to determine how the apparent glycine affinity varied with mutant subunit number. When equal amounts of both NR1 cRNAs were coinjected, a triphasic dose-response curve with high-affinity (HA), intermediate-affinity (IMA), and low-affinity (LA) components resulted (Fig. 1A, Table 1). The corresponding $\mathrm{EC}_{50}$ values for glycine were $0.8 \pm 0.5 \mu \mathrm{M}, 51 \pm 17 \mu \mathrm{M}$, and $4.9 \pm$ $2.2 \mathrm{mM}$, with calculated fractional current contributions of $24 \pm$ $6 \%, 48 \pm 9 \%$, and $28 \pm 7 \%$ for the HA-, IMA- and LAcomponents, respectively (Table 1, Fig. $1 B$ ). Coinjection of the wt and mutant NR1 cRNAs at ratios of 5:1 and 1:5 produced NMDA receptors exhibiting whole-cell currents comparable to those generated at a ratio of 1:1 $(2400 \pm 1100$ and $1900 \pm 800$ $\mathrm{nA}$ ); however, the fractional contributions of the HA-, IMA-, and LA-components changed considerably with the cRNA ratio used (Fig. 1C). At a ratio of 5:1, a biphasic dose-response curve for glycine was obtained with $\mathrm{EC}_{50}$ values of $0.7 \pm 0.4$ and $38 \pm 21$ $\mu \mathrm{M}$ reflecting the HA- and IMA-components, whereas injection at a cRNA ratio of 1:5 created channels displaying $\mathrm{EC}_{50}$ values of $76 \pm 42 \mu \mathrm{M}$ and $8.0 \pm 3.2 \mathrm{mM}$, corresponding to the IMAand LA-components, respectively, without any detectable HA-fraction.

To determine whether the apparent glycine affinities of the
HA-, IMA-, and LA-components, and thus the stoichiometry of incorporated NR1 subunits, may vary in the different NMDA receptor complexes depending on the relative abundances of the NR1 or NR1 ${ }^{\text {Q387K }}$ subunits, we statistically analyzed the distribution of $\mathrm{EC}_{50}$ values of glycine for the HA-, IMA- and LAcomponents at the different ratios of NR1 and NR1 ${ }^{\mathrm{Q} 387 \mathrm{~K}} \mathrm{cRNAs}$ that were injected. If variable numbers of $\mathrm{NR} 1$ or $\mathrm{NR} 1^{\mathrm{Q} 387 \mathrm{~K}}$ subunits are incorporated, the $\mathrm{EC}_{50}$ values of the different fractional components should change with cRNA injection ratios. However, the $\mathrm{EC}_{50}$ values for glycine determined in these experiments were not significantly different from those obtained at a cRNA injection ratio of 1:1 (Fig. 2, Table 1). This indicates that the number of NR1 subunits in the NMDA receptor complex is constant, and that discrete receptor populations are generated on coexpression of the wt and mutant NR1 subunits. Calculation of the relative frequencies of the three channel species generated by the different RNA mixtures according to binominal theory corroborated this interpretation. At an RNA ratio of NR1 to $\mathrm{NR} 1^{\mathrm{Q} 387 \mathrm{~K}}$ of $5: 1$, the relative fractions were $f_{0}=0.6944, f_{1}=$ 0.2777 , and $f_{2} \ll 0.05$ (0.0277), corresponding to NMDA receptor populations in which $69 \%$ of the receptors contained two wt NR1 subunits, $27.7 \%$ both wt and mutant NR1 subunits, and 3\% 


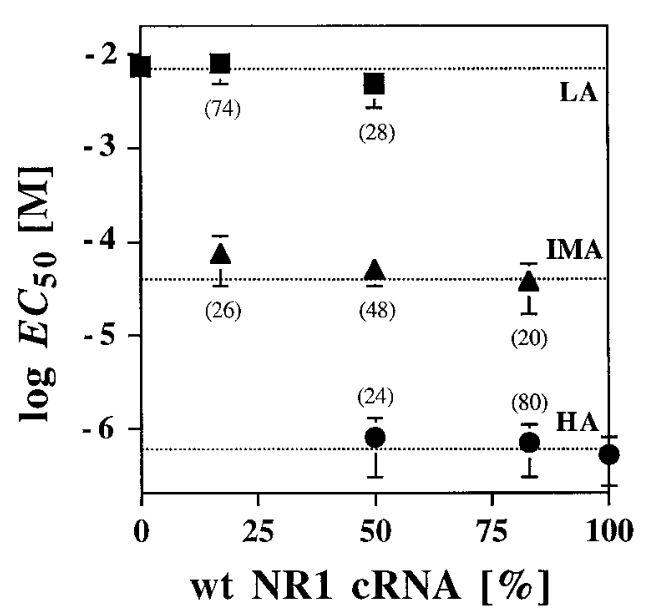

Figure 2. Glycine affinities of the different NMDA receptor populations generated by coexpressing the wt NR1 and NR1 ${ }^{\text {Q387K }}$ subunits with $\mathrm{NR} 2 \mathrm{~B}$. The $\mathrm{EC}_{50}$ values of the HA-, IMA-, and LA-components obtained on coinjection of different ratios of the NR1 and NR1 $1^{\mathrm{Q} 387 \mathrm{~K}}$ cRNAs as described in Figure 1 are plotted as a function of the relative fraction of the wt NR1 cRNA injected (the number of experiments is given in Table 1 ). The dashed lines represent the mean of the $\mathrm{EC}_{50}$ values determined at different cRNA ratios; error bars represent SD. Values in parentheses represent the relative fraction of the current contribution of each component. Note that the $\mathrm{EC}_{50}$ values of glycine for the different current components are independent of the relative ratios of cRNAs injected.

two mutant NR1 subunits. Analysis of the experimental points according to Equation 2 without consideration of the low abundance LA channel species ( $<3 \%$ of the total current) resulted in an excellent fit corresponding to relative fractions of $80 \pm 9 \%$ and $20 \pm 9 \%$ for the HA- and IMA-channels, respectively (Table 1). The same procedure was used to determine the relative proportions of the IMA- and LA-components for the 1:5 cRNA ratio and yielded relative abundances of $26 \pm 13 \%$ and $74 \pm 13 \%$ for the IMA- and LA-components (Table 1). These data are consistent with the presence of two copies of the NR1 subunit in the NMDA receptor channel complex.

\section{Glutamate response properties of channels generated on coexpression of wt and mutant NR2B with wt NR1 subunits}

The mode of analysis described above was also extended to the NR2B subunit. To this end, cRNA encoding either the wt NR2B or the mutant NR2B ${ }^{\mathrm{E} 387 \mathrm{~A}}$ subunit was injected with the wt NR1 RNA into Xenopus oocytes, and the L-glutamate response properties of the resulting receptors were analyzed in the presence of saturating concentrations of glycine. On expression of the wt NR2B subunit, superfusion of L-glutamate evoked maximal membrane currents with an amplitude of $3600 \pm 1000 \mathrm{nA}$ and an $\mathrm{EC}_{50}$ value for L-glutamate of $1.5 \pm 0.5 \mu \mathrm{M}$ (Table 2). A significant reduction of L-glutamate affinity $\left(\mathrm{EC}_{50}=363 \pm 65 \mu \mathrm{M}\right)$ without loss in gating efficacy $\left(I_{\max }=3300 \pm 700 \mathrm{nA}\right)$ was obtained with the NR2B ${ }^{\text {E387A }}$ mutant (Table 2). These values are consistent with our previous data (Laube et al., 1997). We then coinjected the wt NR2B and the mutant NR2B ${ }^{\text {E387A }}$ cRNAs at ratios of 5:1, 1:1, and 1:5. On coexpression of equal amounts of both NR2 cRNAs, a L-glutamate dose-response curve was obtained with a maximal current amplitude of $I_{\max }=2900 \pm 400$ nA (Table 2) that appeared to be composed of at least two components (Fig. 3). The glutamate affinities of its discrete fractions proved difficult to calculate; this probably reflects the smaller difference in glutamate affinities of the wt and low-affinity NR2B subunits ( $\sim 250$-fold) as compared with that in glycine affinities of the wt and low-affinity NR1 subunits ( $\sim 10,000$-fold). Nevertheless, these data could be fitted to Equation 2, assuming the presence of three different channel species, with a predominant intermediate affinity of $\sim 30 \mu \mathrm{M}$. When the NR2B cRNAs of the wt and mutant subunit were coexpressed at ratios of 5:1 and 1:5, the resulting hetero-oligomeric NMDA receptors showed whole-cell currents comparable to those determined for the $\mathrm{wt}$ hetero-oligomers $(4200 \pm 1300$ and $2500 \pm 900 \mathrm{nA})$. However, in contrast to the weakly triphasic dose-response relation seen at the RNA ratio of 1:1 (Fig. 3), now clearly biphasic current/agonist concentration relationships were seen (Fig. 3). For the NR2B/ NR2B ${ }^{\mathrm{E} 387 \mathrm{~A}}$ ratio of 5:1, dose-response curves with $\mathrm{HA}$ - and IMA-components were obtained that showed $\mathrm{EC}_{50}$ values for L-glutamate of $1.3 \pm 0.8$ and $33 \pm 19 \mu \mathrm{M}$, respectively (Fig. 3, Table 2). Coexpression of the NR2B and the NR2B ${ }^{\mathrm{E} 387 \mathrm{~A}}$ subunit at a ratio of 1:5 resulted in IMA- and LA-components with $\mathrm{EC}_{50}$ values of $23 \pm 13$ and $380 \pm 93 \mu \mathrm{M}$, respectively (Fig. 3, Table 2). Again, according to binominal theory the relative fractions of the three putative channels species generated at a cRNA ratio of 5:1 should be $f_{0}=0.6944, f_{1}=0.2777$, and $f_{2} \ll 0.05$ (0.0277). The experimental points were therefore fitted to Equation 2 without considering the low abundance LA-channel species, resulting in relative fractional contributions of $72 \pm 10 \%$ and $28 \pm 10 \%$ for the HA- and IMA-components, respectively (Table 2). Conversely, the IMA- and LA-components generated at an RNA ratio of 1:5 were calculated to have relative abundancies of $33 \pm$ $12 \%$ and $67 \pm 12 \%$, respectively (Table 2 ). Comparison of the apparent glutamate affinities of the HA-, IMA-, and LAcomponents determined from the different injection experiments revealed no significant differences in the corresponding $\mathrm{EC}_{50}$ values for glutamate (Table 2). These data suggest that two copies of the NR2B subunit are present in the heteromeric receptor protein, and that the number of NR2 subunits in the NMDA receptor complex is invariant.

\section{Incorporation of negative dominant subunits}

To further verify the copy number of NR1 and NR2 subunits in the heteromeric NMDA receptor, we coexpressed the nonfunctional NR1 ${ }^{\text {R505K }}$ (Hirai et al., 1996) and NR2B ${ }^{\text {R493K }}$ (Laube et al., 1997) subunits with wt NR1 or wt NR2B, respectively, at varying cRNA ratios. The arginine residue found at position 505 of NR1 and position 493 of NR2B is conserved among all known members of the glutamate receptor subunit family, including non-NMDA receptors, and its substitution leads to nonfunctional channels (Uchino et al., 1992; Hirai et al., 1996; Kawamoto et al., 1997; Laube et al., 1997). cRNAs transcribed in vitro from the $\mathrm{NR} 1^{\mathrm{R} 505 \mathrm{~K}}$ or $\mathrm{NR} 2 \mathrm{~B}^{\mathrm{R} 493 \mathrm{~K}}$ subunit cDNAs fail to create functional channels on coinjection with NR2 or NR1 cRNA into oocytes (Hirai et al., 1996; Laube et al., 1997). This cannot be attributed to assembly incompetence of the NR1 $1^{\mathrm{R} 505 \mathrm{~K}}$ or the NR2B ${ }^{\text {R493K }}$ subunit, because coexpression of these mutants with the wt NR1 or wt NR2B subunit caused a strong reduction in the $I_{\max }$ value at stoichiometric cRNA concentrations (Fig. 4A,B). Because neither glycine nor glutamate affinities were changed on coexpressing $\mathrm{NR} 1^{\mathrm{R} 505 \mathrm{~K}}$ or $\mathrm{NR} 2 \mathrm{~B}^{\mathrm{R} 493 \mathrm{~K}}$ at different ratios with the respective wt proteins (Fig. $4 C$ ) (and data not shown), the reduction in $I_{\max }$ should directly reflect the number of mutant subunits incorporated. We therefore examined the relative contributions of the NR1 and NR2B subunits to receptor function by injecting wt NR1 or NR2B with mutant $\mathrm{NR} 1^{\mathrm{R} 505 \mathrm{~K}}$ or 
Table 2. L-Glutamate dose-response properties obtained on coexpression of different ratios of the NR2B wild-type and NR2B ${ }^{\mathrm{E387A}}$ mutant subunits with the NR1 subunit

\begin{tabular}{|c|c|c|c|c|c|}
\hline cRNAs injected & $\mathrm{EC}_{50}(\mu \mathrm{M})$ & $n_{\mathrm{H}}$ & $I_{\max }(\mathrm{nA})$ & Fractional current $(\%)$ & $n$ \\
\hline NR2B & $1.5 \pm 0.5$ & $1.5 \pm 0.2$ & $3600 \pm 1000$ & & 9 \\
\hline $\mathrm{NR} 2 \mathrm{~B}+\mathrm{NR} 2 \mathrm{~B}^{\mathrm{E} 387 \mathrm{~A}}(5: 1)$ & & & $4200 \pm 1300$ & & 3 \\
\hline HA-component & $1.3 \pm 0.8$ & $1.5 \pm 0.2$ & & $872 \pm 10$ & \\
\hline IMA-component & $33 \pm 19$ & $1.3 \pm 0.4$ & & $28 \pm 10$ & \\
\hline LA-component & n.d. & & & & \\
\hline $\mathrm{NR} 2 \mathrm{~B}+\mathrm{NR} 2 \mathrm{~B}^{\mathrm{E} 387 \mathrm{~A}}(1: 1)$ & & & $2900 \pm 400$ & & 4 \\
\hline HA-, IMA-, LA-component & n.d. & & & & \\
\hline $\mathrm{NR} 2 \mathrm{~B}+\mathrm{NR} 2 \mathrm{~B}^{\mathrm{E} 387 \mathrm{~A}}(1: 5)$ & & & $2500 \pm 900$ & & 3 \\
\hline HA-component & n.d. & & & n.d. & \\
\hline IMA-component & $23 \pm 13$ & $1.2 \pm 0.4$ & & $33 \pm 12$ & \\
\hline LA-component & $380 \pm 93$ & $1.7 \pm 0.1$ & & $67 \pm 12$ & \\
\hline$N R 2 B^{E 387 A}$ & $363 \pm 65$ & $1.4 \pm 0.2$ & $3300 \pm 700$ & & 3 \\
\hline
\end{tabular}

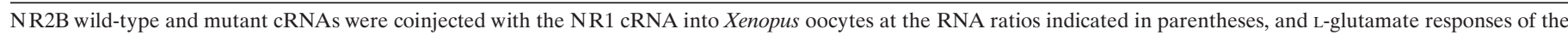

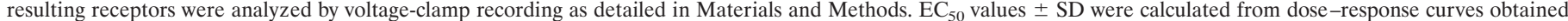

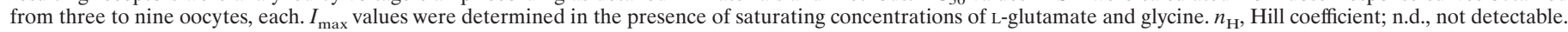
HA, High-affinity; IMA, intermediate-affinity; LA, low-affinity components of mixed receptor populations.

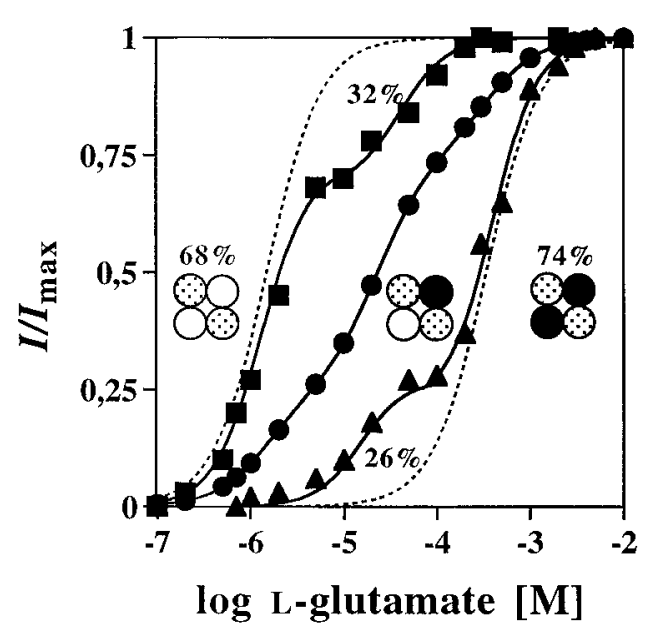

Figure 3. Membrane currents in oocytes coexpressing NR1, wt NR2B, and mutant NR2B ${ }^{\mathrm{E} 387 \mathrm{~A}}$ subunits. Glutamate dose-response curves obtained from oocytes injected with the NR2B and NR2B ${ }^{\text {E387A }}$ cRNAs at ratios of $(\mathbf{O})$ 1:1, (⿴囗十) 5:1, and $(\mathbf{\Delta})$ 1:5 are shown. Note the clearly biphasic shape of the glutamate dose-response curves obtained at the 5:1 and 1:5 cRNA injection ratios. The corresponding $\mathrm{EC}_{50}$ values of the HA- and IMA-, or IMA- and LA-current components are 1.3 and $42 \mu \mathrm{M}$, or 22 and $360 \mu \mathrm{M}$, with fractional contributions of 68 and $32 \%$, or 26 and $74 \%$, respectively, of the maximal current. The solid lines represent leastsquares fits of the modified Hill equation (Eq. 2) assuming the presence of three different channel species. The dashed lines correspond to the doseresponse curves of the pure $\mathrm{NR} 2 \mathrm{~B}$ and $\mathrm{NR} 2 \mathrm{~B}^{\mathrm{E} 387 \mathrm{~A}}$ high- and low-affinity components. Data from individual oocytes are shown; all measurements were repeated on at least three different oocytes with similar results. The mean $( \pm \mathrm{SD})$ of the $\mathrm{EC}_{50}$ values and the Hill coefficients calculated from these experiments are summarized in Table 2. The subunit compositions predicted for the respective tetrameric NMDA receptor complexes are indicated schematically, with $\bigcirc$ representing NR2B wt, $\mathrm{NR}^{2} \mathrm{~B}^{\mathrm{Q} 387 \mathrm{~K}}$, and $:$ NR1.

NR2B ${ }^{\mathrm{R} 493 \mathrm{~K}}$ cRNAs at various concentration ratios $(1: 0 ; 1: 0.25$; $1: 0.5 ; 1: 1 ; 1: 2 ; 1: 5)$ into oocytes, together with the complementary NR2B or NR1 cRNAs. This caused a decrease in inducible whole-cell responses with increasing amounts of the mutant cRNAs, as expected for a dominant negative effect (Fig. 4A,B). Notably, at a 1:1 cRNA ratio, the residual $I_{\max }$ value was only
$24 \pm 6 \%$ for $\mathrm{NR} 2 \mathrm{~B}^{\mathrm{R} 493 \mathrm{~K}}$ and $17 \pm 10 \%$ for $\mathrm{NR} 1^{\mathrm{R} 505 \mathrm{~K}}$ of that seen when the respective wt cRNA was injected alone. This is consistent with the stochastic incorporation of a single copy of the nonfunctional subunit into a tetrameric protein. Indeed, the $I_{\max }$ cRNA ratio relation shown in Figure $4 A, B$ was fitted best with theoretical incorporation values of 1.7 and 2.2 for the NR2B and NR1 mutant subunits, respectively. Thus, two and not three NR1 and NR2B subunits seem to be present within the NMDA receptor hetero-oligomer. This result is consistent with the number of NR1 and NR2 subunits estimated by coexpressing the low-affinity mutants $\mathrm{NR} 1^{\mathrm{Q} 387 \mathrm{~K}}$ and NR2B ${ }^{\mathrm{E} 387 \mathrm{~A}}$, respectively (Figs. 1, 3). Moreover, it argues strongly against the presence of nonbinding "silent" subunit copies that would not be detected by doseresponse analysis of the hybrid receptors.

\section{DISCUSSION}

This study describes an electrophysiological approach to determine the subunit composition of heteromeric NMDA receptors. By varying the ratio of coexpressed wt and low-affinity mutant subunits and examining the resulting dose-response relations, we conclude that two NR1 and two NR2 subunits are present in the recombinant NMDA receptor complex. Similarly, our analysis of the negative dominant effects of the $\mathrm{NR} 1^{\mathrm{R} 505 \mathrm{~K}}$ and $\mathrm{NR} 2 \mathrm{~B}^{\mathrm{R} 493 \mathrm{~K}}$ mutant seen on coexpression with wt NMDA receptor subunits is consistent with the presence of two copies of the NR1 and NR2B subunits, each, within functional NMDA receptors. We therefore conclude that NMDA receptors-and by inference from the existing sequence homologies, ionotropic glutamate receptorsare likely to be tetrameric proteins.

It should be noted that our conclusion is based on two assumptions. First, we assume that wt and mutant subunits are assembled with similar efficiencies. The comparable maximal current amplitudes obtained at various ratios of wt and mutant cRNAs strongly support this premise (Tables 1, 2). Also, when expression times were varied in other experiments (B. Laube, unpublished observations), the relative fractions of the HA-, IMA-, and LAcomponents were not altered, suggesting that wt and mutant polypeptides are synthesized at similar rates. Second, we propose that the mutations that were introduced predominantly affect agonist binding rather than channel gating. This is consistent with 

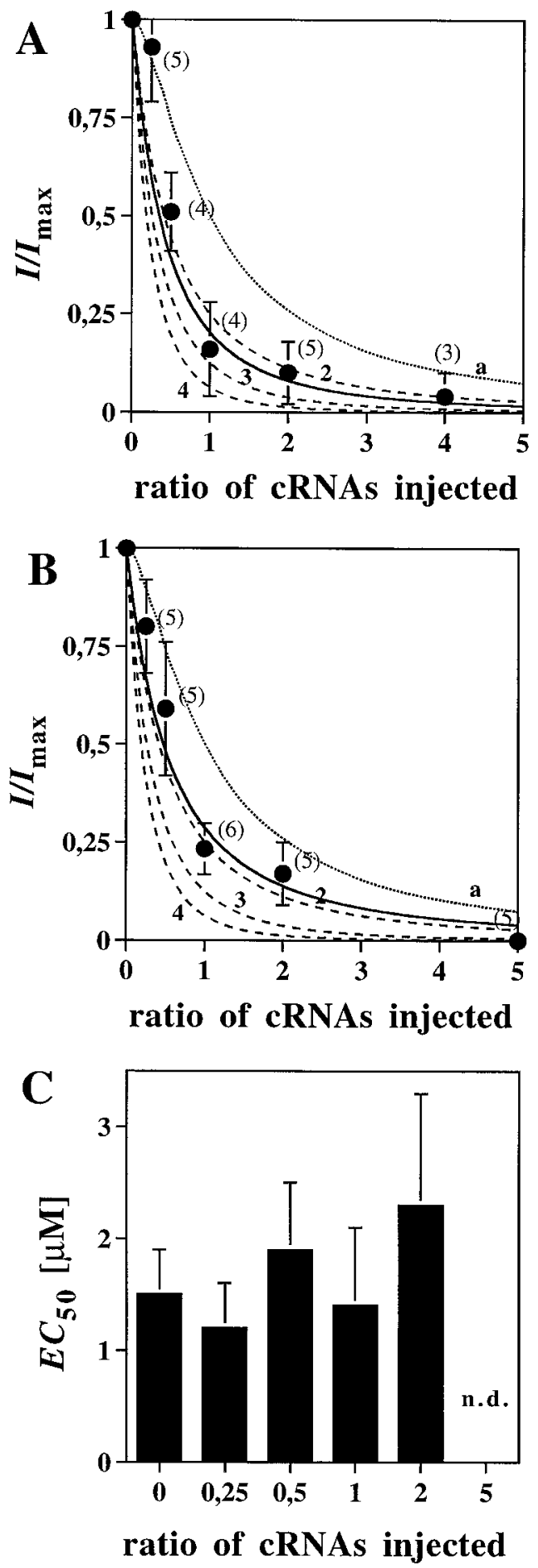

Figure 4. Incorporation of negative dominant NMDA receptor subunit mutants. $A$, Inactivation of NMDA receptor current on coexpression of the NR1 and NR1 ${ }^{\text {R505K }}$ subunits together with the NR2B protein. Membrane currents were determined in oocytes coinjected with different ratios of the NR1 and NR1 ${ }^{\text {R505K }}$ cRNAs; relative inducible whole-cell currents are plotted against increasing NR1 ${ }^{\mathrm{R} 505 \mathrm{~K}} / \mathrm{NR} 1 \mathrm{cRNA}$ ratios. The solid line represents the least-squares fit for the inactivation curve (calculated copy number of $\left.2.2 ; r^{2}=0.94\right)$. The dashed lines represent theoretical inactivation curves, assuming the presence of two (2), three (3), or four (4) NR1 subunits, and full inactivation on incorporation of a single NR1 ${ }^{\text {R505K }}$ polypeptide; these could be fitted to the experimental data with correlation coefficients of $r^{2}=0.91,0.75$ and 0.58 , respectively. The dotted line $(a)$ corresponds to the expected inactivation curve for an NMDA receptor containing three copies of the NR1 subunit, assuming the dramatic shift in $\mathrm{EC}_{50}$ values seen with all the mutants (Kuryatov et al., 1994; Laube et al., 1997) used in this study (for discussion, see Amin and Weiss, 1993; Colquhoun and Farrant, 1993).

In previous reports, the subunit stoichiometries of ionotropic glutamate receptors, including the NMDA receptor subtype, could not be clearly established. Sedimentation analysis and chemical cross-linking of non-NMDA glutamate receptors have produced contradictory data, although most results have been interpreted as being indicative of a pentameric assembly (Blackstone et al., 1992; Wenthold et al., 1992; Brose et al., 1993; Wu and Chang, 1994). For example, chemical cross-linking of AMPA receptors has suggested the presence of five subunits (Wenthold et al., 1992; Brose et al., 1993), whereas velocity sedimentation data revealed a significantly lower molecular mass consistent with ionotropic glutamate receptors being tetrameric proteins (Henley and Oswald, 1988; Blackstone et al., 1992; Wu and Chang, 1994). Analysis of the activation kinetics of native NMDA receptor channels revealed a kinetic model with two glutamate and two glycine binding sites (Benveniste and Mayer, 1991; Clements and Westbrook, 1991). A recent report exploiting the differential sensitivity of wt and mutant AMPA receptor GluR1 subunits to ion channel blockers proposes a pentameric structure for glutamate receptors (Ferrer-Montiel and Montal, 1996).

To theoretically analyze possible stoichiometries on NMDA receptor subunits, Sutcliffe et al. (1996) generated $\beta$-barrelbased models assuming tetrameric, pentameric, and hexameric assemblies. Apart from the number of subunits, the main differences between these models arise from alterations in the pore size of the ion channel. Comparison of its predicted diameter with the available experimental evidence supported a pentameric structure, although a tetramer could not be definitely excluded. However, the conclusions reached from such modeling approaches strongly depend on the structural assumptions made. Notably, some previous expression data on recombinant NMDA receptors are in excellent agreement with the results obtained here. Wafford et al. (1993) showed that hetero-oligomeric NMDA receptors can contain at least two different types of NR2 subunits. Similarly, coexpression of NR1 wt and channel mutant subunits has been reported to produce intermediate conductance states (Béhé et al., 1995);

that incorporation of a single copy of the negative dominant subunit would not impair channel function; the calculated correlation coefficient for our data is $r^{2}=0.64$. $B$, Inactivation of NMDA receptor current on coexpression of the NR2B and NR2B ${ }^{\text {R493K }}$ subunits together with the NR1 protein. Membrane currents were measured and analyzed as described in $A$. The least-squares fit for the inactivation curve gave a calculated copy number of $1.7\left(r^{2}=0.97\right)$. The respective correlation coefficients for the theoretical inactivation curves obtained from assuming the presence of two (2), three (3), or four (4) copies of the NR2 subunit are $r^{2}=0.93,0.74$, and 0.53 , respectively. The inactivation curve predicted for three NR2 subunits with a putative single "silent" copy (a) fitted with a correlation coefficient of $r^{2}=0.74$ only. Agonist concentrations used were $100 \mu \mathrm{M}$ glutamate and $10 \mu \mathrm{M}$ glycine. All data were normalized to the responses obtained on coinjecting the NR1 and the $\mathrm{NR} 2 \mathrm{~B}$ cRNAs alone and represent the mean $\pm \mathrm{SD}$ (values in brackets represent the number of experiments). $C, \mathrm{EC}_{50}$ values obtained from the glutamate dose-response relations determined on coexpression of the NR2B and NR2B ${ }^{\text {R493K }}$ subunits at the indicated cRNA ratios. Note that incorporation of the $\mathrm{NR} 2 \mathrm{~B}^{\mathrm{R} 493 \mathrm{~K}}$ mutant into the NMDA receptor has no significant effect on apparent glutamate affinity. n.d., Not determined because of a low current-response. 
this was taken as evidence for the presence of two copies of the NR1 subunit in the functional NMDA receptor. A recent study published after submission of this manuscript, however, has challenged this interpretation. Using a strategy identical to that of Béhé et al. (1997), Premkumar and Auerbach (1997) obtained data consistent with three NR1 and two NR2 subunits being assembled in the NMDA receptor channel. At present, we have no explanation for the discrepancies between this report and our results.

The subunit composition of the NMDA receptor predicted from our analysis differs markedly from that of other postsynaptic ligand-gated ion channels, i.e., the members of the nicotinic acetylcholine receptor superfamily, which all are pentameric membrane proteins (Betz, 1990; Changeux et al., 1992). Notably, however, both voltage-gated potassium channels (MacKinnon, 1991; Liman et al., 1992) and cyclic nucleotidegated channels (Root and MacKinnon, 1993), i.e., membrane proteins known to be tetramers, resemble glutamate receptors in having reentrant loop domains that form the ion channel (for review, see MacKinnon, 1995). Significant sequence homology has been noted between the channel loop domains of these ion channels and the corresponding reentrant M2 segment of glutamate receptor subunits (Wo and Oswald, 1995; Wood et al., 1995). Thus a shared tetrameric structure of glutamate receptors and the ion channel proteins mentioned above may reflect a similar organization of the respective pore regions, although the latter display different orientations with respect to their topology in the plane of the plasma membrane (McKinnon, 1995).

\section{REFERENCES}

Amin J, Weiss DS (1993) GABA $_{\mathrm{A}}$ receptor needs two homologous domains of the $\beta$-subunit for activation by GABA but not by pentobarbital. Nature 366:565-569.

Béhé P, Stern P, Wyllie D, Nasser M, Schoepfer R, Colquhoun D (1995) Determination of NMDA NR1 subunit copy number in recombinant NMDA receptors. Proc R Soc Lond B Biol Sci 262:205-213.

Benveniste M, Mayer ML (1991) Kinetic analysis of antagonist action at $N$-methyl-D-aspartic acid receptors. Two binding sites each for glutamate and glycine. Biophys J 59:560-573.

Betz H (1990) Homology and analogy in transmembrane channel design: lessons from synaptic membrane proteins. Biochemistry 29:3591-3599.

Blackstone CD, Moss SJ, Martin LJ, Huganir R (1992) Biochemical characterization and localization of a non-NMDA receptor in rat brain. J Neurochem 58:1118-1126.

Brose N, Gasic GP, Vetter DE, Sullivan JM, Heinemann SF (1993) Protein chemical characterization and immunocytochemical localization of the NMDA receptor subunit NMDAR1. J Biol Chem 268:22663-22671.

Changeux JP, Galzi JL, Devillers-Thiéry A, Bertrand D (1992) The functional architecture of the acetylcholine nicotinic receptor explored by affinity labeling and site-directed mutagenesis. Q Rev Biophys 25:395-432.

Clements JD, Westbrook GL (1991) Activation kinetics reveal the number of glutamate and glycine binding sites on the $N$-methyl-D-aspartate receptor. Neuron 7:605-613.

Colquhoun D, Farrant M (1993) The binding issue. Nature 366:510-511.

Durand GM, Gregor P, Zheng X, Bennett MV, Uhl GR, Zukin RS (1992) Cloning of an apparent splice variant of the rat $N$-methyl-Daspartate receptor NMDAR1 with altered sensitivity to polyamines and activators of protein kinase C. Proc Natl Acad Sci USA 89:9359-9363.

Ferrer-Montiel AV, Montal M (1996) Pentameric subunit stoichiometry of a neuronal glutamate receptor. Proc Natl Acad Sci USA 93:2741-2744.

Gasic GP, Hollmann M (1992) Molecular neurobiology of glutamate receptors. Annu Rev Physiol 54:507-536.

Henley JM, Oswald RE (1988) Solubilization and characterization of kainate receptors from goldfish brain. Biochim Biophys Acta 937:102-111.

Hille B (1992) Ionic channels of excitable membranes. Sunderland, MA: Sinauer.

Hirai H, Kirsch J, Laube B, Betz H, Kuhse J (1996) The glycine binding site of the $N$-methyl-D-aspartate receptor subunit NR1: identification of novel determinants of co-agonist potentiation in the extracellular M3-M4 loop region. Proc Natl Acad Sci USA 93:6031-6036.

Hollmann M, Boulter J, Maron C, Beasley L, Sullivan J, Pecht G, Heinemann S (1993) Zinc potentiates agonist-induced currents at certain splice variants of the NMDA receptor. Neuron 10:943-954.

Johnson JW, Ascher P (1987) Glycine potentiates the NMDA response in cultured mouse brain neurons. Nature 325:529-531.

Kawamoto S, Uchino S, Xin KQ, Hattori S, Hamajima K, Fukushima J, Mishina M, Okada K (1997) Arginine-481 mutation abolishes ligandbinding of the AMPA-selective glutamate receptor channel $\alpha 1$-subunit. Mol Brain Res 47:339-344.

Kleckner NW, Dingledine R (1988) Requirement for glycine in activation of NMDA-receptors expressed in Xenopus oocytes. Science 241:835-837.

Kuhse J, Laube B, Magalai D, Betz H (1993) Assembly of the inhibitory glycine receptor: identification of amino acid sequence motifs governing subunit stoichiometry. Neuron 11:1049-1056.

Kuryatov A, Laube B, Betz H, Kuhse J (1994) Mutational analysis of the glycine-binding site of the NMDA receptor: structural similarity with bacterial amino acid-binding proteins. Neuron 12:1291-1300.

Kutsuwada T, Kashiwabuchi N, Mori H, Sakimura K, Kushiya E, Araki K, Meguro H, Masaki H, Kumanishi T, Arakawa M, Mishina M (1992) Molecular diversity of the NMDA receptor channel. Nature 358:36-41.

Laube B, Kuryatov A, Kuhse J, Betz H (1993) Glycine-glutamate interactions at the NMDA receptor: role of cysteine residues. FEBS Lett 335:331-334.

Laube B, Hirai H, Sturgess M, Betz H, Kuhse J (1997) Molecular determinants of agonist discrimination by NMDA receptor subunits: analysis of the glutamate binding site on the NR2B subunit. Neuron 18:493-503.

Liman ER, Tytgat J, Hess P (1992) Subunit stoichiometry of a mammalian $\mathrm{K}^{+}$channel determined by construction of multimeric cDNAs. Neuron 9:861-871.

MacKinnon R (1991) Determination of the subunit stoichiometry of a voltage-activated potassium channel. Nature 350:232-235.

MacKinnon R (1995) Pore loops: an emerging theme in ion channel structure. Neuron 14:889-892.

Meguro H, Mori H, Araki K, Kushiya E, Kutsuwada T, Yamazaki M, Kumanishi T, Arakawa M, Sakimura K, Mishina M (1992) Functional characterization of a heteromeric NMDA receptor channel expressed from cloned cDNAs. Nature 357:70-74.

Monyer H, Sprengel R, Schoepfer R, Herb A, Higuchi M, Lomeli H, Burnashev N, Sakmann B, Seeburg PH (1992) Heteromeric NMDA receptors: molecular and functional distinction of subtypes. Science 256:1217-1221.

Moriyoshi K, Masu M, Ishii T, Shigemoto R, Mizuno N, Nakanishi S (1991) Molecular cloning and characterization of the rat NMDA receptor. Nature 354:31-37.

Nakanishi S (1992) Molecular diversity of glutamate receptors and implications for brain function. Science 258:597-603.

Nakanishi N, Axel R, Shneider NA (1992) Alternative splicing generates functionally distinct $N$-methyl-D-aspartate receptors. Proc Natl Acad Sci USA 89:8552-8556.

Olney JW (1990) Excitotoxic amino acids and neuropsychiatric disorders. Annu Rev Pharmacol Toxicol 30:47-71.

Premkumar LS, Auerbach A (1997) Stoichiometry of recombinant $\mathrm{N}$-methyl-D-aspartate receptor channels inferred from single-channel current patterns. J Gen Physiol 110:485-502.

Root MJ, MacKinnon R (1993) Identification of an external divalent cation-binding site in the pore of a cGMP-activated channel. Neuron 11:459-466.

Sugihara H, Moriyoshi K, Ishii T, Masu M, Nakanishi S (1992) Structures and properties of seven isoforms of the NMDA receptor generated by alternative splicing. Biochem Biophys Res Commun $185: 826-832$.

Sutcliffe MJ, Wo ZG, Oswald RE (1996) Three-dimensional models of non-NMDA glutamate receptors. Biophys J 70:1575-1589.

Uchino S, Sakimura K, Nagahari K, Mishina M (1992) Mutations in a 
putative agonist binding region of the AMPA-selective glutamate receptor channel. FEBS Lett 308:253-257.

Wafford KA, Bain CJ, Le Bourdellès B, Whiting PJ, Kemp JA (1993) Preferential co-assembly of recombinant NMDA receptors composed of three different subunits. NeuroReport 4:1347-1349.

Wafford KA, Kathoria M, Bain CJ, Marshall G, Le Bourdellès B, Kemp JA, Whiting PJ (1995) Identification of amino acids in the $N$-methyl$\mathrm{D}$-aspartate receptor NR1 subunit that contribute to the glycine binding site. Mol Pharmacol 47:374-380.

Watkins J, Krogsgaard-Larsen P, Honoré T (1990) Structure activity relationships in the development of excitatory amino acid receptor agonists and competitive antagonists. Trends Pharmacol Sci 11:25-33.
Wenthold RJ, Yokotani N, Doi K, Wada K (1992) Immunochemical characterization of the non-NMDA glutamate receptor using subunit specific antibodies. J Biol Chem 267:501-507.

Wo ZG, Oswald RE (1995) Unraveling the modular design of glutamate-gated ion channels. Trends Neurosci 18:161-168.

Wood MW, VanDongen HMA, VanDongen AMJ (1995) Structural conservation of ion conduction pathways in $\mathrm{K}$ channels and glutamate receptors. Proc Natl Acad Sci USA 92:4882-4886.

Wu TY, Chang YC (1994) Hydrodynamic and pharmacological characterization of putative alpha-amino-3-hydroxy-5-methyl-4isoxazolepropionic acid kainate-sensitive L-glutamate receptors solubilized from pig brain. Biochem J 3000:365-371. 